
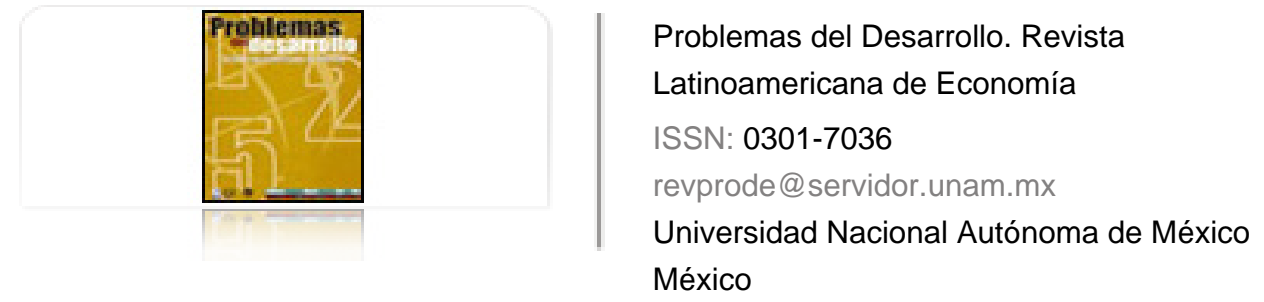

Bekerman, Marta; Rikap, Cecilia

Heterogeneidad estructural y microemprendimientos pobres en la Argentina Problemas del Desarrollo. Revista Latinoamericana de Economía, vol. 43, núm. 169, abril-junio, 2012, pp. 121-144

Universidad Nacional Autónoma de México

Distrito Federal, México

Disponible en: http://www.redalyc.org/articulo.oa?id=11823064006

Cómo citar el artículo

- Número completo

- Más información del artículo

Página de la revista en redalyc.org

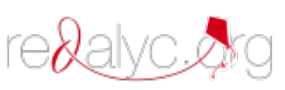

Sistema de Información Científica

Red de Revistas Científicas de América Latina, el Caribe, España y Portugal Proyecto académico sin fines de lucro, desarrollado bajo la iniciativa de acceso abierto 
Revista Problemas del Desarrollo, 169 (43), abril-junio 2012

\title{
Heterogeneidad ESTRUCTURAL Y MICROEMPRENDIMIENTOS POBRES EN LA ARGENTINA
}

\author{
Marta Bekerman* y Cecilia Rikap**
}

Fecha de recepción: 4 de marzo de 2011. Fecha de aceptación: 22 de noviembre de 2011.

\section{RESUMEN}

La heterogeneidad de la estructura productiva en Argentina diferencia sectores con distinto grado de desarrollo tecnológico y posibilidades de acumulación. Esto pone en cuestión la visión ortodoxa de una estructura homogénea del capital y evidencia la necesidad de políticas específicas para cada sector. El llamado sector informal, compuesto principalmente por microempresas con escaso o nulo excedente, constituye uno de los sectores más vulnerables de la estructura productiva argentina. Por ello nos proponemos analizar el funcionamiento de este sector a partir de una encuesta realizada a 100 microempresas pobres de la zona sur de la Ciudad de Buenos Aires. Asimismo, a partir de los resultados obtenidos y de un análisis de las políticas públicas que repercuten sobre el sector, se realizan propuestas de políticas principalmente vinculadas a salir de la informalidad, mayor capacitación y financiamiento.

Palabras clave: Heterogeneidad estructural, microempresas, pobreza, políticas públicas, Argentina.

\section{STRUCTURAL HETEROGENEITY AND POOR MICROENTERPRISES IN ARGENTINA}

\begin{abstract}
The heterogeneity of productive structure in Argentina distinguishes sectors with different levels of technological development and accumulation possibilities. This calls into question the orthodox vision of a homogeneous capital structure and highlights the need for specific policies for each sector. The so called informal sector, made up principally of microenterprises with little or no surplus, is one of the most vulnerable sectors within Argentine productive structure. For this reason, we propose to examine the operation of this sector through a survey conducted with one hundred poor microenterprises in the south of Buenos Aires. By examining the results of the survey and through analysis of the public policies that have repercussions for the sector, policies are suggested that call for a departure from informality and an improvement in training and funding.

Keywords: Structural heterogeneity, microenterprises, poverty, public policies, Argentina.

* Profesora titular de la Universidad de Buenos Aires, Argentina. Correo electrónico: bekerman@econ.uba.ar

** Asistente de investigación de la Universidad de Buenos Aires, Argentina. Correo electrónico: ceciliarikap@gmail.com
\end{abstract}


Marta Bekerman y Cecilia Rikap

\section{HÉTÉROGÉNÉITÉ STRUCTURELLE ET MICRO-ENTREPRISES PAUVRES EN ARGENTINE \\ Résumé}

l'hétérogénéité de la structure productive en Argentine distingue des secteurs de différents niveaux de développement technologique et possibilités d'accumulation. Ceci met en question la vision orthodoxe d'une structure homogène du capital et met en évidence le besoin de politiques spécifiques pour chaque secteur. Le dénommé secteur informel, composé principalement de micro-entreprises à excédent faible ou nul, constitue un des secteurs les plus vulnérables de la structure productive argentine. C'est pourquoi nous nous proposons d'analyser le fonctionnement de ce secteur à partir d'une enquête réalisée sur 100 micro-entreprises pauvres de la zone sud de la ville de Buenos Aires. De même, à partir des résultats obtenus et d'une analyse des politiques publiques qui ont une incidence sur ce secteur, nous faisons des propositions de politiques principalement en lien avec la sortie de l'informalité et l'accroissement de la formation et du financement.

Mots clés : hétérogénéité structurelle, micro-entreprises, pauvreté, politiques publiques, Argentine.

\section{HETEROGENEIDADE ESTRUTURAL E MICRO-EMPREENDIMENTOS POBRES NA ARGENTINA}

Resumo

A heterogeneidade da estrutura produtiva na Argentina diferencia setores com distintos grados de desenvolvimento tecnológico e possibilidades de acumulaçáo. Isso póe em dúvida a visão ortodoxa de uma estrutura homogênea do capital e deixa em evidencia a necessidade de políticas especificas para cada setor. O chamado setor informal, composto principalmente por micro-empresas com escasso ou nulo valor agregado, constitui um dos setores mais vulneráveis da estrutura produtiva argentina. Por isso nos propusemos a analisar o funcionamento deste setor a partir de uma pesquisa realizada a 100 microempresas pobres da zona sul da cidade de Buenos Aires. Assim mesmo, a partir dos resultados obtidos e de uma análise das políticas públicas que repercutem sobre o setor, se fazem propostas de políticas principalmente vinculadas à saída da informalidade, maior capacitação e financiamento.

Palavras-chave: Heterogeneidade estrutural, micro-empresas, pobreza, políticas publicas, Argentina.

阿根廷的结构异质性和微型企业困境

摘要：阿根廷生产结构的异质性体现在各行业不同的技术发展水平和积累能 力上。这便对传统资本结构异质性的观点提出了质疑, 并需要对每个产业部 门制定具体的政策。被称之为非正规部门的行业主要由不具备资本积累能力 的微型企业构成, 是阿根廷生产结构中最为脆弱的行业之一。因此, 我们建 议, 调查布宜诺斯艾利斯南部一百个经营困难的微型企业, 以评估这个行业 的运行状况。通过分析调查结果和已有政策的影响, 提出的政策建议认为, 应该减少非正规行业，并加强人力培训和融资支持。

关键词: 结构异质性, 微型企业, 贫困, 公共政策, 阿根廷 
Heterogeneidad estructural y microemprendimientos pobres en la Argentina

\section{INTRODUCCIÓN}

Los graves problemas económicos sufridos por las economías latinoamericanas durante las últimas décadas generaron un desarrollo cada vez mayor de pequeños emprendedores/as o microempresas que llevan adelante actividades por cuenta propia para producir y vender bienes y servicios en el mercado.

A diferencia de otros países de Latinoamérica, el auge de las microempresas en Argentina es un fenómeno reciente y que cobra mayor relevancia como una solución alternativa al desempleo (Bekerman et al., 2005: 5-6). Pero bajo este esquema, no resulta extrańo que, a diferencia de lo que sucede en los países desarrollados, la gran mayoría de las microempresas sean de subsistencia o presenten bajos niveles de ingreso.

Esta realidad nos plantea la coexistencia dentro del sistema productivo de sectores económicos que presentan una fuerte diferenciación en los niveles de productividad, lo que se traduce en la existencia de una estructura social muy heterogénea y nos remite a un concepto clave de la teoría latinoamericana del desarrollo: el de heterogeneidad estructural.

A partir de las nuevas particularidades que presenta la estructura productiva argentina aparecen nuevas tipificaciones de los distintos estratos ocupacionales que exhiben marcadas diferencias en lo que hace a su capacidad para generar excedentes. Dentro de los mismos se encuentra el segmento bajo o informal que se compone, principalmente, de emprendimientos con baja productividad o hasta de subsistencia. Es aquí donde se insertan las microempresas.

De hecho, este grupo pasó de tener un rol marginal a ser considerado por los gobiernos y organismos internacionales como un sector productivo con fuertes potencialidades para aliviar los problemas del desempleo y la pobreza. Esta reflexión aparece ligada al fuerte crecimiento en el empleo y los ingresos que tuvo lugar en muchos países de la región como Bolivia, Perú y Colombia a partir del desarrollo de las microempresas. En definitiva, el aumento en su productividad se convirtió en un instrumento importante en la lucha contra la pobreza y la marginalidad y, en consecuencia, en el fortalecimiento de los procesos democráticos.

En la Argentina las microempresas informales y generadoras de bajos niveles de acumulación presentan una participación que no es menor dentro de la población económicamente activa. Se trata de un segmento que enfrenta una problemática muy diferente a la del resto de los estratos productivos. Por eso, a diferencia de lo sucedido en el pasado, una política orientada a reducir la marginalidad debería focalizarse sobre el conocimiento de dicha problemática. 
En este marco, el objetivo de este trabajo es diagnosticar la situación de un conjunto de microempresas pobres de la ciudad de Buenos Aires. ${ }^{1}$ Las mismas son parte de un estrato productivo cuya dinámica debería estudiarse para poder realizar propuestas de política que generen ganancias de productividad y contribuyan al desarrollo de microempresas sustentables.

Comenzaremos con un breve desarrollo del concepto de heterogeneidad estructural y su aplicación a la estructura productiva argentina. Luego, se analizarán las características de los microempresarios del segmento informal en la ciudad de Buenos Aries a través de la encuesta realizada. Entonces, se presentará la visión de dichos microempresarios sobre las políticas que pueden afectarlos, mientras que en la sección 4 se observarán las políticas existentes. Finalmente, están las conclusiones y propuestas de políticas para el sector.

\section{LA HETEROGENEIDAD ESTRUCTURAL Y LOS ESTRATOS ECONÓMICOS EN LA ARGENTINA}

La economía argentina sufre la persistencia de marcadas desigualdades que fueron agravadas por las reformas neoliberales que tuvieron lugar a partir de mediados de los años setenta. En efecto, las políticas de desregulación económica, liberalización financiera y apertura comercial -acompañadas por un tipo de cambio fijo en paridad con el dólar entre 1992 y 2002- habrían ampliado los diferenciales tecnológicos entre y en el interior de cada rama. Al mismo tiempo, habrían generado excedentes relativos de población "sobrante" y una mayor segmentación de los mercados de trabajo y de las relaciones sociales (Nun, 1969; Cimoli, Primi y Pugno, 2006).

Esta realidad se vincula con el concepto de heterogeneidad estructural, un elemento clave de la teoría latinoamericana del desarrollo, que adquiere nueva vigencia para evaluar la exclusión en América Latina. Plantea la coexistencia de sectores económicos con una fuerte diferenciación en los niveles de productividad, lo que se traduce en la existencia de una estructura social muy heterogénea, dentro de los sistemas productivos de los países periféricos.

Este concepto entra en contraposición con supuestos fundacionales de la economía neoclásica: la homogeneidad del capital y la existencia de un agente

1 Se trata de microempresas ubicadas en las zonas de Soldati y Mataderos, consideradas como las más pobres dentro del área de la capital federal. 
representativo e hiperracional que asigna recursos en forma óptima para alcanzar su maximización de beneficios. En cambio, asume microfundamentos shumpeterianos basados en que la heterogeneidad de los agentes: de distintos niveles de competencia, de grados de acceso y capacidad de procesamiento de la información. Los agentes evolucionan a partir de efectos de aprendizaje. Ello vuelve necesario especificar sus comportamientos (Bekerman y Monti Hughes, 2010).

En la Argentina la heterogeneidad estructural y la persistencia de formas de producción marginadas no son sólo una herencia del pasado, sino un rasgo que se reprodujo a partir de políticas económicas que despreciaron su impacto sobre la pobreza. Esa heterogeneidad se ha profundizado, haciendo más complejas las relaciones entre el sector excluido y el resto de la economía. La consecuencia se presenta como un sistema productivo más desarticulado que el prevaleciente previo a las reformas neoliberales, donde la informalidad cobra fuerza.

Con el final de la crisis de comienzos del siglo inició un rápido proceso de recuperación y crecimiento económico favorecido por el contexto internacional. Los cambios en la política macroeconómica generaron a partir de 2003, una importante recuperación de la actividad industrial que posibilitó una caída del desempleo y de la pobreza. Para las capas más pobres, el nuevo modelo económico les permitió ampliar las capacidades de subsistencia y consumo, pero no transformó sus condiciones estructurales de marginación. Es decir, el núcleo duro de la exclusión mantiene las condiciones de producción y reproducción.

Un trabajo reciente (Coatz et al., 2010: 56-60) distingue la existencia de al menos tres estratos en las actividades productivas, a saber: un segmento de producción de bienes y servicios ubicado en torno a la frontera internacional. Un segundo segmento de estrato medio que agrupa a un conjunto de empresas pequeńas y medianas y a ocupados y desocupados de alta calificación. En tercer lugar, el segmento bajo o sector informal incluye a pequeñas firmas y servicios generadores de escaso valor agregado, trabajadores que se desempeñan por cuenta propia al no poder insertarse en el mercado laboral, formado por microempresas o comercios ligados a situaciones de precariedad laboral y trabajo familiar. Su participación no es menor dentro de la PEA, ya que las economías de subsistencia abarcarían al 16.6\%, al tiempo que las pequeñas y microempresas de productividad baja o marginal alcanzarían al 12.6\%. Este estrato productivo enfrenta problemáticas específicas a ser atendidas (Coatz, et al., 2010; 59). 
Marta Bekerman y Cecilia Rikap

\section{EL SECTOR INFORMAL DE VILLAS DE EMERGENCIA DEL SUR DE LA CIUDAD DE BUENOS AIRES ${ }^{2}$}

Para la realización de este trabajo partimos de diferentes fuentes de información disponibles en Avanzar: capacitadores, coordinadores, oficiales de créditos y de información extraída de trabajos ya realizados sobre los microempresarios prestatarios de Avanzar (Renaud e Iglesias, 2008). Estas fuentes orientaron la selección del instrumento de recolección de información y el tipo de formulario que se aplicaría. Los productores viven mayoritariamente en villas de emergencia, su trabajo no está registrado, tienen muy escasos recursos para la producción, son extranjeros en un porcentaje importante, entre otros datos relevantes. Esto nos hizo priorizar la aplicación de un formulario principalmente precodificado que permitiera relevar indicadores objetivos de necesidades o problemas y no preguntas de opinión subjetivas que pondrían de manifiesto sus limitaciones para expresarse libremente.

Se utilizó como instrumento de recolección de datos una encuesta por muestreo aplicada a 100 microempresarios seleccionados al azar a partir de bases de prestatarios y antiguos prestatarios de la asociación civil Avanzar. La muestra trató de dar cuenta de las diferencias existentes en el universo según: i) tipo de actividad económica (alimenticia, textil, otra), ii) barrio (Piletones 29 casos, Soldati 14 casos, Fátima 13 casos, Ciudad Oculta 22 casos, InTA 5 casos y otros 6 casos), iii) sexo y iv) antigüedad en Avanzar. Para seleccionar la proporción de entrevistados según cada categoría se tuvo en cuenta la información censal de las villas así como también la información contenida en las bases de datos de Avanzar. ${ }^{3}$

Cabe señalar que el estrato productivo bajo estudio no sólo presenta heterogeneidades en relación a los otros segmentos de la sociedad sino también dentro de su propio entorno, como podremos observar a lo largo del trabajo. Para

2 Este estudio se hizo con base en una encuesta realizada en el año 2010 a 100 microempresarios que habitan en las villas de emergencia de Los Piletones, Villa 3 (Barrio de Fátima) y Villa 15 (Ciudad Oculta) de la Ciudad de Buenos Aires. Sin embargo, los datos sobre ingresos netos sólo pudieron obtenerse para 90 emprendimientos.

3 La encuesta fue realizada entre los meses de enero y marzo del 2010. Los emprendedores fueron entrevistados en las oficinas de Avanzar ubicadas en Villa Soldati y en un comedor de la Villa Ciudad Oculta. Los datos obtenidos fueron procesados utilizando el programa spss el cual cuenta con herramientas específicas para el análisis de datos. 
reflejar estas diferencias presentaremos una tipología de emprendedores teniendo en cuenta sus niveles de ingresos netos ${ }^{4}$ y la subcategorización realizada por Coatz et al. (2010: 56-60) dentro del estrato III, "Sector Informal". Se obtuvieron las clasificaciones según el Cuadro 1, donde se resumen los resultados de la encuesta según estos niveles de ingreso.

Cuadro 1. Tipo de emprendimiento según los niveles de ingreso: ${ }^{5}$

\begin{tabular}{lcc}
\hline \multicolumn{1}{c}{ Tipo de emprendimiento } & $\begin{array}{c}\text { Cantidad de emprendimientos } \\
\text { (en número y en porcentaje) }\end{array}$ \\
\hline De infra subsistencia (hasta \$1600) & 22 & $24.40 \%$ \\
De subsistencia (entre \$1601 y \$2400) & 29 & $32.20 \%$ \\
Con pequeños excedentes (mayor a \$2400) & 39 & $43.30 \%$ \\
Total & 90 & $100 \%$ \\
\hline
\end{tabular}

Fuente: Elaboración propia con base en la encuesta de campo.

Podemos observar que la mayoría corresponde a microempresas "con pequeńos excedentes" seguidos por los de "subsistencia" y, en último lugar, por los de "infrasubsistencia". A continuación analizaremos el comportamiento de ciertas variables estructurales explicativas del resultado económico como la forma social del trabajo y la dotación de recursos productivos que presentan estos emprendimientos.

4 Cabe señalar que la determinación del nivel de ingresos netos correspondientes a los microempresarios presentó dificultades ligadas a una correcta evaluación de los entrevistados acerca de los rubros que los componen. Por eso las preguntas formuladas en la encuesta permitieron realizar una cuidadosa reconstrucción, paso a paso en pesos de diciembre de 2009 a marzo de 2010, del ingreso por ventas al que se le descontaron los gastos de la semana anterior a la realización de la entrevista. Con este dato del ingreso neto semanal se calculó el mensual al multiplicarlo por las cuatro semanas del mes.

5 Esta clasificación incluye el resultado de 90 encuestas (sobre un total de 100 realizadas) dado que las mismas han sido aquellas en las cuales fue posible determinar, en forma clara, el ingreso neto. 
Marta Bekerman y Cecilia Rikap

\section{Forma social del trabajo}

La forma social del trabajo da cuenta de las relaciones sociales de producción en el emprendimiento. Se construye a partir de dos indicadores: $a$ ) quién/es es/son el/los titular/es del emprendimiento (unipersonal, familiar ${ }^{6}$ o una sociedad de hecho $^{7}$ ) y b) si contratan o no trabajo asalariado en forma permanente, temporaria o de ambos tipos.

La mayor parte de las microempresas encuestadas se basan en el trabajo del productor y/o su familia. En efecto, se trata mayoritariamente de emprendimientos unipersonales y familiares de dos o más miembros, los cuales no contratan asalariados o lo hacen en forma temporaria.

Cuadro 2. Forma social del trabajo por tipo de emprendimiento (cantidad y porcentajes)

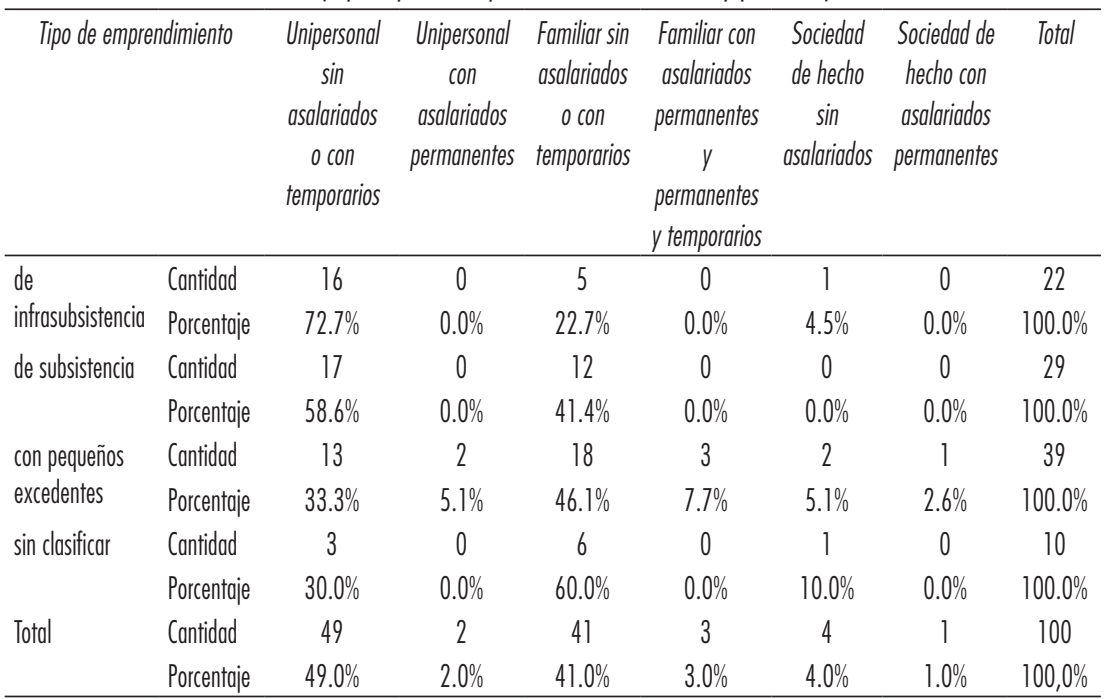

Fuente: Elaboración propia.

6 Tanto el trabajo unipersonal como el familiar pueden entrar en la categoría de trabajo familiar (entendido como unidades en las cuales existe presencia del trabajo del productor y/o de su familia en forma directa en las labores). Pero para efectos de simplificar el análisis los consideraremos como categorías separadas: unipersonal y familiar.

7 Se trata de dos o más personas que comparten capital, que realizan trabajo directo en las labores, y que se asocian de hecho sin conformar ninguna forma jurídica para encarar una actividad. 
Nos preguntamos qué tienen en común y qué es lo que diferencia a los emprendedores analizados. En común tienen una forma social del trabajo de tipo familiar o unipersonal, dado que no se contratan asalariados salvo temporariamente para algunas tareas y/o épocas del año, como las fiestas. Y los diferencia el tipo de reproducción del capital: para algunos el ingreso no alcanzaría a la reproducción simple de la actividad económica (infrasubsistencia), otros obtienen ingresos al nivel de la reproducción simple de su emprendimiento (subsistencia) y los que están en mejores condiciones, son los que presentan un nivel de reproducción ampliada de su capital aunque con un pequeño excedente. Sin embargo, estas diferencias no son tan importantes como para dar lugar a la presencia de asalariados permanentes en este último subsegmento, si bien allí se concentran los escasos negocios con asalariados permanentes.

Por otra parte, más allá de que se observen microempresas con pequeños excedentes, una dificultad de largo plazo que atañe a todo el sector informal es la escasa reinversión de las ganancias -en muchos casos porque las mismas son prácticamente inexistentes- lo que frena las posibilidades de crecimiento más allá de su reproducción simple (Bekerman, 2009: 526).

La fuerza de trabajo total existente en los 100 negocios es de 168 trabajadores, incluyendo al dueño del negocio. Una característica estructural es la baja dotación de trabajadores y asimismo, que éstos aumentan en la medida en que nos movemos desde los de infrasubsistencia hacia aquéllos con pequeños excedentes.

Un dato que revela cómo se enfrentan los empresarios a los límites de su productividad es que el 65\% dedica más de 40 horas semanales al negocio. Los microempresarios "con pequeños excedentes" y "de subsistencia" en una amplia mayoría trabajan más de 40 horas semanales ( 80 y 69\%, respectivamente). En cambio, en los emprendimientos de infrasubsistencia, la mayoría (59\%) trabaja 40 horas semanales o menos. Es decir que la duración de la jornada laboral está muy vinculada al tipo de emprendimiento medido por sus resultados económicos.

\section{Dotación de recursos e infraestructura}

El análisis de la dotación de recursos productivos nos lleva a preguntarnos acerca de la cantidad de máquinas promedio y de la infraestructura disponible por las empresas analizadas. Cabe señalar que algunos emprendimientos no requieren maquinaria. El caso más evidente es el correspondiente al comercio textil que involucra fuertemente a los emprendimientos de infrasubsistencia. Éste es uno de los motivos por los que el 68\% de los emprendimientos de infrasubsistencia no dispone de maquinarias o dispone de ellas en un escaso número. 
En los emprendimientos de subsistencia, se repite la tendencia a disponer de poco stock de maquinaria ya que el $31 \%$ no los utiliza. En cambio, los emprendimientos con pequeńos excedentes utilizan maquinaria en casi todos los casos. Es decir que ésta es una variable estructural relevante en relación con los resultados económicos de los emprendedores.

En este marco, cuando se preguntó a los entrevistados si las máquinas y herramientas que tenían eran suficientes y adecuadas, la mayor parte de quienes disponen de maquinaria contestaron que la cantidad era suficiente pero que su calidad no era la adecuada. La mayoría de los encuestados, principalmente los de subsistencia y aquéllos con pequeños excedentes que utilizan maquinaria mostraron sus preocupaciones en cuanto a la necesidad de renovar sus máquinas. Es que, aun cuando se reconozca lo inadecuada que es su dotación de capital fijo, se observa una falta de reinversión en nuevas máquinas incluso en lo que respecta al reemplazo de capital amortizado (Bekerman, 2009: 526-527).

Por otra parte, la disponibilidad de infraestructura "espacio físico separado del hogar para el negocio" constituye un problema central. No sólo para aquellos que carecen de espacio propio para su negocio (51\%), también para quienes cuentan con el mismo, dado que en la mayoría de los casos las condiciones de dicho espacio distan de ser las adecuadas.

Respecto al lugar de venta de los productos se observa una asociación positiva importante con el tipo de emprendimiento. En efecto, en los emprendimientos de infrasubsistencia y de subsistencia predomina la venta en la casa del emprendedor (32 y $38 \%$ respectivamente), mientras que en los emprendimientos con pequeńos excedentes predomina la venta en más de un lugar, principalmente en ferias y locales fuera de la casa ( $23 \%$ en cada caso).

\section{Financiamiento}

Otro elemento que debe considerarse es el acceso al crédito. Ninguno de los emprendimientos considerados ha accedido a créditos por medio del sistema formal. Por el contrario, su acceso se produjo a través de una institución sin fines de lucro que les otorga microcréditos. ${ }^{8}$ Otra forma de acceso al financiamiento, aunque sólo es utilizada por el $9 \%$ de los encuestados, destinada únicamente a

8 Se trata de la Asociación Civil Avanzar por el Desarrollo Humano (www.avanzar.org.ar) a la que pertenece la mayor parte de los microempresarios entrevistados. 
la comunidad boliviana, es el Pasanaco. ${ }^{9}$ También operan en los barrios prestamistas informales, conocidos como "usureros". Un reclamo particular es el acceso al crédito para la compra de maquinarias por montos elevados. El 83\% de los encuestados no recibió créditos con esta finalidad aunque enfatizó que los requeriría para progresar en su actividad.

Otra dimensión importante que se indagó, se refiere a la gestión financiera. Es decir, hasta qué punto los prestatarios pueden gestionar en forma autónoma sus necesidades de financiamiento o, en concreto, calcular la necesidad de crédito. La encuesta mostró que sólo el 56\% calcula de alguna forma cuánto dinero necesita cuando solicita financiamiento. La explicación que se destaca, entre quienes no realizan el cálculo, es que aceptan lo que consiguen. Hasta cierto punto esta respuesta reflejaría que la experiencia de racionamiento del crédito vivida largamente por estos emprendedores los lleva a tomar el máximo que la institución estuviera dispuesta a otorgarles. Por otra parte, podría señalar que el crédito recibido es insuficiente.

\section{Forma jurídica}

Por forma jurídica se analiza si la microempresa cuenta o no con alguna figura legal, es decir, si se trata de una entidad jurídica consolidada -y en ese caso de qué tipo: sociedad anónima, sociedad de responsabilidad limitada, sociedad de hecho, etcétera. Los resultados obtenidos señalan que ningún emprendimiento tiene figura jurídica ya sea como sociedad civil o comercial y el $91 \%$ no está inscrito en la AFIP. Por otro lado, sólo el 1\% de los emprendimientos está inscrito en el Registro de Establecimientos y en el Registro de Productos y el 95\% desconoce el sistema de Monotributo Social que otorga el Ministerio de Desarrollo Social. ${ }^{10}$ No sólo se trata de un sector altamente informal, sino que también

9 Se trata de un grupo integrado, generalmente, por 10 a 20 personas. Cada persona aporta un monto establecido y se crea un pozo. Este pozo lo retira alguna de las integrantes (se sortean las ubicaciones para ello) y cuando lo devuelve lo retira la siguiente persona. El uso es definido por el receptor del dinero.

10 En el Registro Nacional de Efectores del Ministerio de Desarrollo Social, los emprendedores pueden inscribirse como monotributistas sociales por una cuota mínima, lo que les permite facturar y tener acceso a una obra social. Los años como monotributista se consideran a afectos de la jubilación aunque para que ésta se efectivice deben hacerse los aportes correspondientes. 
presenta una fuerte carencia de información respecto de las normativas vigentes y de las posibilidades de formalización.

\section{Escolaridad y acceso a capacitación}

La asociación positiva entre educación y trabajo ha sido demostrada históricamente en innumerables estudios. De todas maneras, dada la situación actual de la educación pública, la heterogeneidad del mercado de trabajo y las múltiples estrategias de subsistencia que adoptan las familias, esta asociación tiene matices que aparecen en los resultados de la encuesta.

Se observa una falta de asociación positiva fuerte entre los tres tipos de emprendimiento y el nivel de escolaridad, lo que revela una situación frecuente en la pos crisis 2001-2002. Que un porcentaje importante de los emprendedores tenga estudios secundarios incompletos o más (61\%), o la existencia de personas con estudios superiores (7\%), indicaría que la escolaridad no es un reaseguro frente a la subocupación, los bajos ingresos o la pobreza.

El nivel de escolaridad alcanzado en los emprendimientos en condiciones de infrasubsistencia muestra dos grupos muy diferenciados dentro de este sub-segmento: un núcleo duro de pobreza con baja escolaridad (31\%) y otro conformado por mujeres que tienen esta actividad como un ingreso secundario de la familia y con escolaridad media o alta (69\%). Los ingresos de los cónyuges serían un complemento importante para las economías domésticas teniendo en cuenta la caída del salario real de los trabajadores producida en la última década.

En relación con las actividades de asistencia técnica cabe resaltar que sólo un tercio de los emprendedores señaló haber recibido algún tipo de asistencia durante los últimos tres ańos. Pero la mayoría de los entrevistados (60\%) considera que mejoraría en el desempeño de sus tareas si recibiera capacitación y/o asistencia técnica. Los emprendedores que tienen pequeños excedentes se mostraron más seguros en su desempeño en el negocio y en el manejo de su actividad pero revelaron otras preocupaciones como disponer de más capital de trabajo.

\section{Capacidad de gestión}

Cada vez más se vuelve evidente -tanto en la bibliografía del tema como en el análisis concreto de la realidad- la necesidad de incluir las condiciones de producción y la capacidad de gestión -la cual se vincula con el llamado capital humano-como elementos que pueden aportar luz al análisis de cada estrato productivo. 
Un aspecto vinculado a la gestión se refiere a cómo se compran insumos y materias primas y cómo se venden los productos -individual o asociativamente-, lo que puede afectar los niveles de ingresos debido a la posible realización de economías de escala. Sin embargo, más del 70\% de los entrevistados nunca realizó compras o ventas en conjunto. Sería importante implementar mediante asistencia técnica medidas que incentiven este tipo de estrategias.

En este sentido, es acertado pensar que las microempresas del sector informal no persiguen la obtención de economías de escala. Las mismas podrían lograrse también estableciendo lazos con sus pares para intercambiar información, conocimiento e innovaciones. Aunque aquí se pone de manifiesto otra de sus limitaciones: no tienen, en general, una estrategia de desarrollo de innovaciones y diversificación de productos que les permita aumentar sus ventas. Consecuentemente, la fácil entrada de nuevos oferentes potenciales "que reduce la demanda residual y los ingresos de las empresas establecidas" profundiza la no inversión (Bekerman, 2009: 526).

Por otra parte, una adecuada gestión administrativa de los emprendimientos requiere un registro de ingresos y gastos con el mayor detalle posible. Al respecto, los emprendedores que registran por escrito sus ingresos por ventas alcanzan al $60 \%$. Sin embargo, los porcentajes se reducen con respecto al registro de los costos directos (53\%) y sobre todo de los indirectos (28\%). Se traduce de esto último que las empresas de este sector no cuentan con registros contables del emprendimiento que muestren sus entradas y salidas de dinero y otros activos.

Estos resultados coinciden con los encontrados en otro trabajo confeccionado a partir de una encuesta previa realizada a prestatarios de una asociación civil que otorga microcréditos. Allí se refleja una clara subestimación de ciertos costos indirectos, como los provenientes del desgaste de las máquinas y herramientas utilizadas dentro del proceso de producción, lo que puede derivar en desacumulación de capital fijo, lo que podría llevar al punto de no contar con suficiente dinero a la hora de su reposición (Bekerman, 2009: 528). La marcha del negocio se evalúa por "la caja" que se va haciendo semana a semana (o incluso diariamente).

Estas cuestiones evidencian algunos de los principales problemas que afrontan las empresas del sector informal, a los que se suman la ausencia de estrategias de promoción y comercialización de los productos y el escaso, o incluso nulo, conocimiento acerca de su principal competencia. A su vez, tampoco desarrollan planes de negocios útiles para facilitar la gestión y el seguimiento en el tiempo del negocio (Bekerman, 2009: 526). 
Marta Bekerman y Cecilia Rikap

\section{LA VISIÓN DE LOS MICROEMPRESARIOS SOBRE LAS POLÍTICAS EXISTENTES}

$\mathrm{Al}$ analizar las respuestas de los emprendedores encuestados frente al tema de las políticas públicas existentes lo primero que cabe señalar es un marcado desconocimiento acerca de las mismas y de la forma en que pueden afectarlos. Sólo el 16\% manifestó conocer alguna política de gobierno que le sirva o lo perjudique. Dentro de las escasas respuestas obtenidas aparece la inflación como una cuestión que los impacta de forma negativa. La segunda pregunta -qué debería implementar el gobierno para mejorar su situación- fue respondida por el $86 \%$ de los encuestados y dio lugar a un amplio espectro de respuestas entre las que sobresalen tres ejes fundamentales: los créditos, la salida de la informalidad y la capacitación.

Con respecto al acceso al crédito, solicitan que el Estado cubra esta necesidad en forma directa o que ayude a instituciones sin fines de lucro para que puedan fortalecer su oferta de fondos. El destino más mencionado para su utilización es la adquisición de máquinas y herramientas (28\%). Le sigue el crédito para local, compra, alquiler o refacción (19\%); para comprar mercadería adicional $(16 \%)$; para vivienda y materias primas (14\%), y en último lugar, para empezar un nuevo negocio (9\%). Los montos pedidos varían desde niveles pequeños hasta $\$ 20,000$ y están asociados al destino de los créditos.

En cuanto a la legalización de sus emprendimientos, señalan la existencia de muchas trabas. Destacan el costo y la complejidad que implica el cumplimiento de las normativas vigentes a la hora de intentar salir de la informalidad. Mencionaron, en particular, las dificultades vinculadas a las habilitaciones de los establecimientos y a la obtención del monotributo, lo que les permitiría emitir facturas y circular libremente con sus productos. Cabe señalar que la mayor parte de los prestatarios desconocían la existencia del Monotributo Social.

Es interesante observar que más de la mitad (60\%) de los microempresarios considera que mejoraría en el desempeño de sus tareas si recibiera capacitación y/o asistencia técnica. Entre los que deseaban capacitarse, 45\% nombró aspectos técnicos de la producción, 33\% desea hacerlo en cuestiones contables, 30\% en ventas y $37 \%$ mencionó temas administrativos. Por otra parte, el $17 \%$ de los entrevistados que tiene máquinas y herramientas considera que necesita capacitarse en su manejo y el $15 \%$ en su reparación.

Un segundo grupo de respuestas, menos frecuentes, se vinculan al desarrollo de mercados: disponer de lugares fijos y puestos en las ferias, formas cooperativas para comercializar y promoción de exportaciones. Por otro lado, surgen 
temas vinculados a la calidad de vida: control de la inflación, más trabajo, situación del barrio (calles, acceso, seguridad) y mejoras en las viviendas, ya sea a través de donaciones o créditos.

\section{LAS POLÍTICAS SOCIALES EN ARGENTINA Distintas visiones sobre las políticas sociales}

Desde una primera aproximación, podríamos definir a las políticas sociales como aquellas que buscan fortalecer la equidad y/o mejorar la distribución. El primer objetivo apunta a asegurar la igualdad de oportunidades para las distintas personas, mientras que las mejoras en la distribución, que pueden ser vía ingresos o activos, buscan resolver las situaciones de desigualdad social. Las políticas de redistribución de ingresos (no incluimos aquí a las de tipo salarial) pueden presentar, en muchos casos, un carácter asistencial, mientras que las que se orientan a la redistribución de activos (de educación, de capacitación y las socio-productivas en general) claramente tienen un enfoque de desarrollo de capacidades. Por otro lado, tanto las políticas asistenciales como las que persiguen la redistribución de activos pueden ser focalizadas o universales. Es decir, pueden apuntar a un sector específico de la población que cumpla con ciertos requisitos explicitados, o ser abiertas a toda la comunidad.

Desde otra perspectiva Bonvecchi y Smulovitz (2008: 127-139) presentan tres visiones predominantes acerca de la política social. En un primer grupo incluyen a quienes la consideran como regeneradora de lazos sociales y hacen hincapié en reintegrar a la sociedad a los excluidos, distinguiendo entre pobres recientes y pobres estructurales. Los pobres recientes tendrían la capacidad de reinsertarse en la economía de mercado, no así los estructurales. Es por ello que la política social debe ser focalizada. Esto la haría más eficiente, dada la segmentación mencionada y los menores recursos requeridos en comparación con estrategias de carácter universal. Este grupo priorizaría entonces políticas productivas incluyendo la provisión de microcréditos, construcción de capacidades asociativas, combate al trabajo infantil, desarrollo de microempresas tuteladas y la transferencia de fondos a organizaciones de base consultadas en el diseño de políticas.

En un segundo grupo se encontrarían aquellos que ven a la política social como una derivación de la política económica. Es decir, el tipo de crecimiento económico buscado determinaría el contenido de la política social. Esta visión apunta a la incorporación de todos los excluidos del mercado de trabajo formal y su acceso a servicios de salud y seguridad social. 
El tercer y último grupo incluye a quienes consideran a la política social como garante de derechos humanos. Es por ello que debe garantizar un mínimo de ingresos (o renta mínima de inserción) y condiciones de vida digna para todos los individuos. Por lo tanto, se prefieren las políticas universales por sobre las focalizadas, las que deberían tender a eliminarse.

La experiencia argentina reciente presenta un amplio espectro de políticas sociales entre las que se destacan, frente a la dramática crisis del 2001, aquéllas orientadas a resolver urgencias de corto plazo, como veremos a continuación.

\section{Programas del gobierno nacional}

En este grupo de políticas se destaca el "Plan Jefes/Jefas de Hogar Desocupados" (PJJHD). El mismo ha sido implementado desde el Ministerio de Trabajo y está destinado a los hogares pobres con hijos menores de 18 años (o bien con hijos discapacitados de cualquier edad) en donde el jefe de hogar se encontrara desocupado. Tuvo sus orígenes en el año 2002 y según el decreto de creación, se trataba de un plan "...para ser aplicado mientras dure la emergencia ocupacional”, por lo que se establecía como fecha límite de vencimiento al 31 de diciembre de 2002. El plan se asentó sobre dos objetivos básicos: generación de empleo y sostenimiento de ingresos. Según un estudio la escasa disponibilidad de elementos materiales y financieros en los municipios, sumada a la falta de asesoramiento tecnológico y a una reducida capacidad de gestión local, determinó que las tareas laborales desempeñadas por los beneficiarios generaran productos de una significación económica reducida y de una utilidad social limitada (Monza y Giacometti, 2003: 15-18). Es decir que esta política se orientaba a dos de los aspectos señalados en la sección anterior: garantizar un nivel mínimo de ingresos (aunque en forma focalizada) y a la incorporación de los beneficiarios al mercado de trabajo. Sin embargo, el segundo aspecto no fue efectivamente implementado por falta de una infraestructura municipal adecuada.

La fecha límite se fue modificando año tras año. Para reducir su influencia se crearon dos programas con objetivos diferentes a los que los destinatarios migrarían de manera optativa: el Programa Familias por la Inclusión Social, en el ámbito del Ministerio de Desarrollo Social (MDS) y el Seguro de Capacitación y Empleo, en el ámbito del Ministerio de Trabajo, Empleo y Seguridad Social (MTESs). Así para octubre de 2008 el número de beneficiarios se había reducido a un millón y medio.

El Seguro de Capacitación y Empleo (scye) brinda apoyo a los trabajadores desocupados en la búsqueda activa de empleo, es decir, busca su reinserción en 
actividades productivas. En su lugar, el Plan Nacional "Familias" se dirige a familias cuya situación es de mayor vulnerabilidad, buscando su inserción social a través de la provisión de un nivel de ingresos mínimos, pensiones asistenciales y trabajo con adolescentes y jóvenes. Como contraprestación tienen la obligación de presentar constancias de concurrencia a la escuela y de realización de los controles de salud correspondientes a esos hijos. El plan también prevé otorgar becas de $\$ 50$ por mes para finalizar estudios (primarios, secundarios y/o formación profesional). En 2010 el porcentaje del presupuesto público destinado a este plan disminuyó por la implementación de la Asignación Universal por Hijo.

Desde 2003, otros programas destinados a asegurar niveles mínimos de provisión de bienes fueron desarrollados desde el Ministerio de Trabajo a través de la unificación de distintas políticas llevadas a cabo en relación a la problemática alimentaria en torno a un único programa llamado "Plan Nacional de Seguridad Alimentaria”. Este programa incluye desde asistencia alimentaria y comedores escolares y comunitarios (a los cuales asisten casi 2 millones de personas) hasta ayuda para autoabastecimiento y autoproducción (para más de 3 millones de personas), capacitación, información y difusión de prácticas alimentarias.

Un paso muy importante en políticas públicas contra la pobreza fue dado en octubre de 2009, cuando se creó la Asignación Universal por Hijo para la Protección Social (AUH), orientada a garantizar un mínimo de ingresos para sectores que se encuentran en la informalidad. Está destinada a los hijos menores de edad o discapacitados (estos últimos de por vida) de desocupados, trabajadores no registrados que ganen menos del salario mínimo, vital y móvil y trabajadores que realicen tareas de servicio doméstico. Por cada hijo (con un máximo de 5 por padre o responsable) se otorgaba $\$ 180$ por mes, de los cuales $\$ 144$ se perciben directamente y $\$ 36$ condicionados a la presentación de certificados de atención médica y escolaridad del menor.

El presupuesto para el 2011 ascendió a \$10,083 millones. Para noviembre de 2010 se habían tramitado asignaciones para casi 3,7 millones de niños de casi 2 millones de familias que reciben $\$ 220$ mensuales.

Según algunas estimaciones la AUH sacó de la pobreza a entre 1,4 y 1,8 millón de personas, de las cuales entre 700 mil y 1,1 millón tienen 18 años o menos. Por otro lado, más de 1 millón de personas abandonaron la condición de indigentes (Panigo et al., 2009: 27). Se espera que la cifra ascienda a 1,4 millones cuando se complete su implementación.

Uno de los desafíos que presentan los programas de tipo asistencial consiste en lograr que los hogares beneficiarios puedan alcanzar una eficaz inserción en el sistema productivo. Esto implica que las personas involucradas puedan recibir, por un lado, los activos necesarios para fortalecer su oferta laboral (capacitación, 
acceso al crédito, etcétera); por el otro, que se genere la demanda necesaria en el mercado de trabajo o de productos (en el caso de microempresas).

En esa línea existen diversos programas sociales orientados a lograr una reinserción en la economía de mercado a través del desarrollo de microempresas productivas. Dentro de este grupo se destaca el Plan Nacional de Desarrollo Local y Economía Social: "Manos a la Obra" impulsado, también, por el Ministerio de Desarrollo Social.

Este plan está integrado por tres componentes: apoyo económico y financiero para microempresas (a través de subsidios y créditos); fortalecimiento institucional por medio de capacitación y asistencia técnica a distintas instituciones gubernamentales y no gubernamentales; y para quienes busquen desarrollar proyectos productivos. Hacia el 2007 sólo el 2,4\% del presupuesto de dicho Ministerio fue destinado a este plan. Para 2004 se sancionó, en línea con el Plan Manos a la Obra, el Monotributo Social, emitido por el Registro Nacional de Efectores de la Economía Social. Permite que los emprendedores salgan de la informalidad, puedan facturar, accedan a una obra social y adquieran antigüedad a los efectos de la jubilación.

En línea con el Plan "Manos a la Obra", a mediados del año 2006 se sancionó en el Congreso la Ley 26117 llamada "Financiamiento de la Economía Social" que es conocida como "Ley de Microcréditos". El artículo primero señala que su objeto central es "regular, promover y desarrollar un sistema de apoyo a la Economía Social, que estimule el desarrollo integral de personas y grupos de escasos recursos". Es decir, se trata de una ley de promoción que apunta esencialmente a fortalecer las Instituciones de Microfinanzas (IMF) existentes. Dentro de las acciones propuestas en el proyecto de ley se creó el Fondo Nacional de Apoyo a la Economía Social. Este Fondo otorga subsidios y préstamos a las IMF y se orienta a robustecer dichas instituciones por medio de la provisión de capacitaciones y asistencia técnica. Como complemento, se creó en 2006 la Dirección Nacional de Comercialización que apoya a los microempresarios en la realización de ferias, rondas de negocios y financiamiento para comercialización. En 2008 se crea la ley de Marca Colectiva para distinguir los productos elaborados y/o servicios prestados por las formas asociativas vinculadas a la economía social.

Con este tipo de políticas que apuntan a lo productivo recientemente se ha puesto en marcha el "Programa Ingreso Social con Trabajo, Argentina Trabaja" desde el Ministerio de Desarrollo Social en conjunto con el Ministerio de Trabajo. El único requisito para incorporarse es no poseer otro ingreso y está destinado tanto a cooperativas como a individuos. Para el 2011 prevé un presupuesto de $\$ 3.345$ millones. 
Desde nuestra perspectiva la política social debe responder a una combinación de las tres estrategias planteadas más arriba. Por un lado, no podemos hablar de una estrategia de crecimiento económico sin considerar la calidad de ese crecimiento. Las políticas económicas deben enfatizar en la equidad y la inclusión social. Las mismas deberían permitir incorporar al mercado formal y alejar de la precariedad a los trabajadores desocupados.

Sin embargo, la realidad nos muestra la existencia de lo que se conoce como un núcleo duro de desempleo, es decir que no es posible, en el corto plazo, terminar con la exclusión. Esto requiere asegurar un ingreso mínimo ciudadano ligado a mejoras en la infraestructura habitacional, de educación y de salud. En este contexto resulta acertada la Asignación Universal por Hijo implementada en la Argentina.

Pero también se necesitan políticas orientadas a profundizar aquellas estrategias orientadas a dar salidas económicas a los sectores que se encuentran en una situación de marginalidad estructural y que no van a ser fácilmente absorbidos por el mercado de trabajo formal. Para ello se vuelve necesario adicionar políticas productivas específicas que tomen en cuenta la especificidad de la población a la que van dirigidas.

\section{CONCLUSIONES Y LINEAMIENTOS DE POLÍTICAS ESPECÍFICAS Resultados del trabajo de campo}

A lo largo del trabajo se evidenciaron las particularidades de las microempresas pobres del sur de la ciudad de Buenos Aires. Como análisis general señalamos que la mayor parte de las mismas son unipersonales y/o familiares. Si bien presentan diferencias en el nivel de reproducción del capital, no son tan importantes como para dar lugar a la presencia de asalariados permanentes. Por esto, pertenecen a lo que se conoce como la economía social o popular.

Un porcentaje importante de los entrevistados dedica más de 40 horas semanales a su negocio, lo que puede estar ligado a bajos niveles de productividad. Por otra parte, generan una baja dotación de trabajadores que aumenta en la medida en que nos movemos desde las microempresas de infrasubsistencia hacia aquéllas con un pequeño excedente. Esto es relevante a la hora de pensar en una política que apunte a consolidar puestos de trabajo en ese sector a través del fortalecimiento de estas microempresas. Teniendo en cuenta, además, que el trabajo es aquí el recurso más abundante, su valorización es un elemento clave.

A pesar de que la mayor parte de los encuestados que utilizan máquinas plantearon la necesidad de su renovación, se observa una falta de reinversión 
aun para reemplazar aquellas que ya están amortizadas. A esto se suma la falta de espacio propio para el negocio. Todo esto puede estar vinculado a la falta de acceso al crédito. Otro aspecto que se debe comentar es el nivel de informalización que se registra en el sector estudiado, que se ve obstaculizado ante la fuerte carencia de información respecto de las normativas vigentes.

A su vez, no se observa un desarrollo de las capacidades de gestión, principalmente por falta de conocimiento tanto de las acciones a llevar a cabo como de sus potenciales beneficios para el negocio. Esto permite la fácil entrada de nuevos oferentes potenciales, lo que reduce la demanda y los ingresos de las empresas establecidas y restringe, por lo tanto, los niveles de inversión. Por otro lado, no cuentan con registros contables del emprendimiento. Esto, sumado a la falta de desarrollos de planes de negocios podría ser útil para facilitar la gestión.

Respecto a las políticas solicitadas por los microempresarios cabe señalar que sólo una parte muy minoritaria manifestó conocer alguna que le sirva o que lo perjudique. Esto vuelve a evidenciar las dificultades de comunicación que presentan las políticas desarrolladas desde el sector público, lo que puede constituir un obstáculo para asegurar su efectividad. Se destacaron tres ejes fundamentales dentro de sus principales necesidades: un mayor acceso al crédito, la salida de la informalidad y un mayor acceso a la capacitación.

A partir de estos resultados del trabajo de campo y del análisis de políticas existentes realizados más arriba, presentaremos algunos lineamientos de política específicos para el sector.

\section{Lineamientos de políticas específicas}

Dentro de las propuestas respecto a la falta de crédito, las Instituciones de Microfinanzas (IMF) pueden cumplir un rol importante en cuanto a asegurar el acceso al crédito a los sectores más pobres de la población. Esto se debe a que la lógica de las microfinanzas requiere de una estructura diferente a la de los créditos convencionales. Si bien algunos bancos comerciales están empezando a incursionar en este campo, su objetivo es ampliar la base de su cartera aunque no siempre incluyen a los sectores más pobres.

En la Argentina, que las IMF no puedan funcionar como instituciones reguladas por el Banco Central les impide actuar como receptoras de depósitos, lo que limita sus mecanismos de financiamiento. Otras limitaciones de tipo institucional son el aún escaso desarrollo de instituciones de apoyo y la limitada articulación entre las mismas. Todo esto hace que el rol de estas instituciones sea todavía muy incipiente y mucho menor que en otros países de América Latina y 
Asia. La Ley Nacional de Microcréditos apunta a promover el desarrollo de estas instituciones, pero se necesitan medidas más profundas en cuanto a financiamiento y regulación.

La capacitación ha sido una de las principales demandas de política; sin embargo, los microempresarios se muestran, a veces, reacios a concurrir a las capacitaciones para no discontinuar su trabajo. Por tratarse de negocios con ganancias consumidas casi por completo por las necesidades del hogar, perder horas de trabajo podría implicar no poder afrontar parte de esas necesidades. Pero, al mismo tiempo, la capacitación les permitiría ganar productividad y desarrollar estrategias de negocio que aporten a su crecimiento. Por esto, consideramos que se debe implementar un plan de becas de asistencia técnica para los emprendedores, que compense económicamente las horas no trabajadas destinadas a capacitación.

La capacitación debe atacar el principal problema del sector: la gestión tanto comercial como financiera y administrativa. Los emprendedores carecen de conocimientos asociados a gestionar eficientemente su negocio. Otro aspecto importante sería el establecimiento de escuelas técnicas en las proximidades de la ubicación geográfica de estos emprendimientos.

Para poder expandir su negocio y salir de la subsistencia también es necesaria la formalización, por ejemplo mediante el Monotributo Social. Sin embargo, su éxito depende de su descentralización. Se necesitan gestores que visiten los negocios con los formularios para completar.

En cuanto a los problemas de infraestructura sería importante que el Estado pueda otorgarles espacios físicos, preferentemente por fuera de las villas de emergencia. Esto facilitaría las ventas hacia fuera de las villas y el cumplimiento de normas de seguridad alimentaria en el caso de las microempresas alimenticias. Asimismo, podrían colocar gestores que faciliten las tareas de habilitación de dichos establecimientos enseñando también los procedimientos necesarios para cumplir las normas de seguridad alimentaria.

Finalmente, una cuestión fundamental para el crecimiento del sector es la implementación de políticas de generación de demanda. Por un lado, el mismo Estado podría orientar parte de su demanda hacia las microempresas pobres. Por otro lado, podría lanzar un plan de créditos con tasa preferencial para aquellas empresas que realicen pedidos al por mayor al sector informal. Esto sería particularmente importante para productores textiles, quienes podrían vender al por mayor su producción incentivándolos a mejorar su capacitación y productividad.

En definitiva, el sector de microemprendimientos de la economía social o popular que trabaja en villas de la ciudad de Buenos Aires requiere de estrategias 
Marta Bekerman y Cecilia Rikap

socio-productivas diferenciadas que contemplen herramientas flexibles que se puedan adecuar a las características que presenta cada uno de los tres tipos de emprendimientos identificados en este estudio.

\section{BIBLIOGRAFÍA}

II Foro Interamericano de la Microempresa, Argentina, 1999.

Banco Central de la República Argentina, "Taller regional. Aspectos regulatorios de las microfinanzas", en Ponencias para el debate, Argentina, PNUD, 2007.

Bekerman, Marta, "Microcréditos y capacitación. Impacto sobre los prestatarios y sobre las instituciones que los otorgan", Revista de Análisis Económico y Social, vol. 59, núm. 7, México, Comercio Exterior, julio de 2009, pp. 523-533.

Microcréditos. Una estrategia contra la exclusión, Argentina, Editorial Norma, 2004.

Bekerman, Marta y Nicolás Monti Hughes, "Estrategias inclusivas en la lucha contra la pobreza", en Revista Realidad Económica, Instituto Argentino para el Desarrollo Económico, núm. 254, 16 de agosto al 30 de septiembre de 2010, pp. 63-81.

Bekerman, Marta, Santiago Rodríguez, Sabina Ozomek y María Iglesias, Microfinanzas en Argentina, Argentina, PNUd, 2005.

Bonvecchi, Alejandro y Catalina Smulovitz, "Atender necesidades, crear oportunidades y garantizar derechos", en Cruces, Guillermo (editor), Los programas sociales en Argentina hacia el bicentenario. Visiones y perspectivas, Argentina, Banco Mundial, 2008, pp. 121-160.

CEDEM (Dirección General de Estadística y Censos), Coyuntura económica de la ciudad de Buenos Aires, Argentina, Ministerio de Hacienda, Gobierno de CABA, 2009.

(Dirección General de Estadística y Censos), La población en las villas de la ciudad, Argentina, Sistema Estadístico de la Ciudad, Gobierno de CABA, 2008.

Cimoli, Mario, Analissa Primi, y Maurizio Pugno, "Un modelo de bajo crecimiento: la informalidad como restricción estructural”, Revista CEPAL, núm. 88, Chile, CEPAL, 2006, pp. 89-107.

Coatz, Diego, Fernando García Díaz y Sergio Woyecheszen, "Acerca de la dinámica creciente de la heterogeneidad productiva y social en la Argentina", Boletín Informativo Techint, núm. 332, Argentina, Techint, 2010, pp. 49-78. 
Gobierno de la ciudad de Buenos Aires, Coyuntura económica de la ciudad de Buenos Aires, núm. 21, Argentina, Ministerio de Producción del Gobierno de CABA, 2007.

Halperin Wisburd, Leopoldo, Juan Labiaguerre, Cecilia, Delpech, María González, Berta Horen, José Villadeamigo, Liliana Siffredi, y Guillermo Muller, Politicas sociales en la Argentina. Entre la ciudadania plena y el asistencialismo focalizado en la contención del pauperismo, Argentina, Cuaderno del CEPED, núm. 10, FCE-UBA, 2008.

Ley 26.117, http://www.infoleg.gov.ar/infolegInternet/anexos/115000119999/118062/norma.htm

Ley 26.355, http://infoleg.mecon.gov.ar/infolegInternet/anexos/135000139999/138933/norma.htm

Madoery, Óscar, Otro desarrollo, Argentina, Universidad Nacional de San Martín, 2008.

Monza, Alfredo y Claudia Giacometti, "Los beneficiarios del Plan Jefes y Jefas de Hogar”, Proyecto Cooperación oit/Gobierno Argentino (MTss), Argentina, Serie Documentos de Trabajo núm. 1, 2003.

Neffa, Julio (editor), Desempleo, pobreza y politicas sociales. Fortalezas y debilidades del Plan Jefes y Jefas de Hogar Desocupados, Argentina, Ed. Miño y Dávila, 2008.

Nun, José, "Superpoblación relativa, ejército industrial de reserva y masa marginal”, en Revista Mexicana de Sociología, vol. 5, núm. 2, México, unam, 1969, pp. 174-236.

Panigo, Damián, Emmanuel Agis y Carlos Cañete, El impacto de la Asignación Universal por Hijo en Argentina, Argentina, Conicet-Ceil Piette, 2009.

Pinto, Aníbal, "Heterogeneidad estructural y modelo de desarrollo reciente de la América Latina”, en Pinto, Aníbal, Inflación: raíces estructurales, México, Fondo de Cultura Económica, 1976 (1970), pp. 104-140.

Renaud, Juliette y María Iglesias, El impacto social de las microfinanzas. El caso de Avanzar, Argentina, CenES fCE de la Universidad de Buenos Aires, 2008.

Salvia, Agustín y Julieta Vera, Heterogeneidad estructural, segmentación laboral y distribución del ingreso en el gran Buenos Aires: 1992-2003, Argentina, Gino Germani, 2006.

Solís, Marcos, Sergio Carbonetto, y Sandra Gioia, Microcrédito para el sector informal urbano, Argentina, Cáritas Diocesana Quilmas, 2001.

Torres, Mario, Microempresa, pobreza y empleo en América Latina y El Caribe. Una propuesta de trabajo, España, Organización de los Estados Americanos, Secretaría Ejecutiva para el Desarrollo Integral, Departamento de Desarrollo Social y Empleo, 2006. 
Marta Bekerman y Cecilia Rikap

Tramutola, Carlos, Informe Asentamientos precarios, Argentina, Dirección General de Estadísticas y Censos, Gobierno de la Ciudad de Buenos Aires, 2002.

Yunus, Muhammad, Hacia un mundo sin pobreza, España, Editorial Andrés Bello, 1997. 